\title{
A INTERNET PODERIA PROMETER HONRAS A UM PRÍNCIPE NOVO? DONALD TRUMP E A PANDEMIA DE COVID-19 NOS ESTADOS UNIDOS ${ }^{1}$
}

\author{
¿PODRÍA INTERNET PROMETER HONORES A UN NUEVO PRÍNCIPE? DONALD \\ TRUMP Y LA PANDEMIA DE COVID-19 EN LOS ESTADOS UNIDOS
}

\author{
COULD THE INTERNET PROMISE HONORS TO A NEW PRINCE? DONALD \\ TRUMP AND THE COVID-19 PANDEMIC IN UNITED STATES
}

\author{
Júlia Volpato MOUTROPOULOS ${ }^{2}$ \\ Vinícius de Souza STURARI ${ }^{3}$
}

RESUMO: Em março de 2020 a Organização Mundial da Saúde decretou o estado de Pandemia pela disseminação do novo Coronavírus Sars-Cov-2, causador da doença Covid-19. As respostas de cada Estado foram diferentes, sendo que nos Estados Unidos, Donald Trump optou por seguir as características que o elegeram, como o negacionismo e a divulgação de Fake News pela internet, impactando nas atitudes da população e levando o país a um elevado número de mortos pela doença. Nesse artigo analisaremos brevemente a eleição de Trump e a gestão da pandemia por seu governo, lançando mão dos conceitos de virtù e fortuna de Maquiavel para tecer nossas análises.

PALAVRAS-CHAVE: Donald Trump. Pandemia. Fake news. Internet.

RESUMEN: Em marzo de 2020, la Organización Mundial de la Salud declaró el estado de pandemia debido a la propagación del nuevo coronavirus Sars-Cov-2, que causa la enfermedad Covid-19. Las respuestas de cada estado fueron diferentes, y em Estados Unidos, Donald Trump optó por seguir las características que lo eligieron, como la negación y la difusión de Fake News em internet, impactando las actitudes de la población y llevando al país a un numero elevado de muertos por la enfermedad. Em este artículo analizaremos brevemente la elección de Trump y la gestión de la pandemia por parte de su gobierno, haciendo uso de los conceptos de virtude y fortuna de Maquiavel para tejer nuestras análisis.

PALABRAS CLAVE: Donald Trump. Pandemia. Fake news. Internet.

ABSTRACT: In March 2020, the World Health Organization declared Pandemic status due to the spread of the new Coronavirus Sars-Cov-2, which causes the Covid-19 disease. The responses from each state was different, and in the United States, Donald Trump chose to

\footnotetext{
1 Agradecemos ao parecerista anônimo pelas sugestões e apontamentos que contribuíram para a melhoria do texto final.

${ }^{2}$ Universidade Estadual Paulista (UNESP), Araraquara - SP - Brasil. Graduanda no curso de Administração Pública. ORCID: https://orcid.org/0000-0002-9756-9345. E-mail: julia.moutropoulos@unesp.br

${ }^{3}$ Universidade Estadual de Campinas (UNICAMP), Campinas - SP - Brasil. Doutorando no Programa de PósGraduação em Ciência Política. Pesquisador do Grupo de Estudo e Pesquisa Participação e Democracia (GEPPADE-FCLAr) e do Núcleo de Pesquisa em Participação, Movimentos Sociais e Ação Coletiva (NEPACUnicamp). ORCID: https://orcid.org/0000-0003-0727-770X. E-mail: v.sturari@gmail.com
} 
follow the characteristics that elected him, such as denial and the dissemination of Fake News on the internet, impacting the population's attitudes and taking the country to a high number of deaths from the disease. In this paper we will briefly analyze Trump's election and his government's management of the pandemic, making use of Machiavelli's concepts of virtù and fortune to weave our analyses.

KEYWORDS: Donald Trump. Pandemic. Fake news. Internet.

\section{Introdução}

Em dezembro de 2019, na cidade chinesa de Wuhan, foram descobertos os primeiros casos de Covid-19, doença causada por um novo tipo de Coronavírus, o Sars-Cov-2. Com a circulação internacional, em pouco tempo outros países também relataram casos da doença e, em 11 de março de 2020, a Organização Mundial da Saúde (OMS) decretou Estado de Pandemia. Esse evento repercutiu no plano político-ideológico de diversas formas, e impactou diretamente as instituições políticas ao redor do mundo, em conjunto com as demais consequências da transmissão do vírus e sua doença.

O contexto no qual os países se depararam com a emergência da pandemia não era estável política ou economicamente. Diante da alta taxa de infecção do vírus, a iminência de uma crise global sem precedentes na contemporaneidade colocou em xeque todo o sistema político, mas principalmente a capacidade de resposta dos Estados e governos, vigente à essa ameaça sistêmica (JARMAN, 2021). Destarte, toda a conjuntura existente é impactada e a crise preexistente funciona até como um catalisador para que a nova se expanda.

Um dos mais importantes aspectos da conjuntura e peça chave do negacionismo, a tendência global à alta circulação de Fake News cria uma "zona cinza" em definir objetivamente os acontecimentos, e cria um ambiente de imprecisão que propicia a relativização de fatos. Sobre o fenômeno das Fake News no campo político, Lee escreve:

Nas democracias, [o fenômeno] "fake news" se desenvolveu em atuais climas políticos, produzindo desinformação em plataformas de mídias sociais. Isso serviu para diminuir a credibilidade de redes de notícias convencionais, dividindo o público geral, ideologicamente e na mera aceitação do fato, fornecendo crédito a afirmações ideológicas de "fake news". Apenas debatido recentemente, [o fenômeno] "fake news" tem sido um componente de estratégias políticas desde o início da prática política moderna (LEE, 2019, p. 16, tradução nossa).

O abalo causado pelas Fake News é notável principalmente nos Estados Unidos, país que foi palco do primeiro pleito eleitoral permeado pelas notícias falsas altamente 
reproduzidas em mídias sociais, que acabaram por eleger o Republicano Donald Trump. O primeiro "Twitter president" (BRUNELLO, 2019) foi invariavelmente problemático ao longo de seu mandato, iniciado em 2016, e é reconhecido pela alta dose de dissimulação e mentira em seus pronunciamentos. Segundo levantamento do Washington Post, publicado por Kessler, Rizzo e Kelly (2018), Trump faz cerca de 7,6 afirmações falsas por dia, que repercutem de forma massiva entre o povo americano, principalmente entre seus eleitores.

A cultura das Fake News, aliada à sua personalidade controversa, tem força relevante no poder exercido pelo presidente estadunidense no período da pandemia, e são fatores decisivos nas consequências de suas decisões políticas para o enfrentamento dessa realidade e para a manutenção do poder. Diante disso, torna-se pertinente uma análise da conduta política de Donald Trump, com enfoque em seu governo no período pandêmico e pré-eleição.

Para isso, nos valeremos dos clássicos conceitos de virtù e fortuna de Nicolau Maquiavel. Assim sendo, esse artigo, composto por mais três partes, perpassará a trajetória política da gestão da pandemia por Donald Trump. Na parte que segue, trataremos dos conceitos elaborados pelo filósofo e pela trajetória política de Donald Trump. Na parte posterior abordaremos brevemente a gestão da pandemia nos Estados Unidos. Por fim, faremos algumas considerações finais sobre o exposto.

\section{Eleição e governo Trump}

Maquiavel considera que um príncipe virtuoso é aquele que, entre outros aspectos, preza pela estabilidade na sua relação com quem o rodeia. $\mathrm{O}$ autor trata de como é preciso se relacionar com mercenários, secretários e bajuladores; porém, o protagonismo dessa buscada "estabilidade" é o povo. Assim, podemos ter uma noção do que o autor trata quando fala sobre a virtù. Já a fortuna é explicada pela comparação com um rio torrencial, pois, "quando enchem e transbordam, [...] tudo cede à sua violência, sem poder se opor a ele" (MAQUIAVEL, p. 133). Em uma reflexão sobre o livre arbítrio, pouco cabe à escolha individual; ele é dominado pelo acaso. Mais que isso, a fortuna é "a força motora do movimento cíclico da história [...], a construtora e a destruidora das formas particulares de poder" (BIGNOTTO, 1991).

Portanto, a atividade política em Maquiavel tem certo enfoque na capacidade do Príncipe em servir-se de ambas, assim como a relação com o povo dominado, já que essa é a força maior capaz de derrubar um príncipe do governo. Nos dias atuais e no contexto da democracia estadunidense, cabe pensar também nos meios que levam alguém à posição de 
governante. Ademais, a política em Maquiavel é desvinculada da ética (desde que não haja corrupção, segundo ele); o foco é apenas na manutenção do poder. Torna-se, dessa forma, pertinente pensar meios para que essa relação seja construída e estável.

É objeto de estudo de muitos intelectuais a ascensão de Donald Trump, uma personalidade controversa e externa à política institucional, à presidência dos Estados Unidos, um país cujo alicerce político tende ao tradicionalismo. Acerca dessa questão, Mark Lilla, em seu livro O Progressista do Ontem e do Amanhã (2018), procura analisar por quais motivos Trump conquistou seu eleitorado. $\mathrm{O}$ autor argumenta que o que trouxe os Estados Unidos até a eleição de Trump foi a incapacidade dos progressistas de construírem uma unidade política, com enfoque no que une os cidadãos em uma nação, e não no que os separa.

Uma das justificativas apresentadas por Lilla (2018) para o forte apoio popular conquistado por Donald Trump é o apelo à discriminação das minorias políticas. $\mathrm{O}$ autor aponta que a política identitária (que ele chama de liberalismo identitário) é um problema para a atividade política, porque não provoca a "adesão" da classe trabalhadora branca e não traz um imaginário de solidariedade coletiva, junto da visão de uma nação com cidadãos em conjunto. Em suma, o autor argumenta que os democratas americanos se negam a despertar o sentimento de identificação, porque trazem propostas bem estruturadas, mas não constroem um imaginário do que querem criar; algo que os Republicanos e a extrema direita têm feito, com demagogia, e que provoca adesão dessa classe trabalhadora branca "abandonada" nos discursos progressistas.

Desse modo, para trazer os argumentos de Lilla de forma sucinta, o imaginário coletivo que leva à eleição de Trump consiste, entre outros pontos, na falta de identificação coletiva e na atividade política pautada pelo individualismo. Para descrever o que chama de Dispensação Reagan (o imaginário coletivo em questão), ele expõe:

I- A boa vida é a vida dos indivíduos autônomos - indivíduos alicerçados talvez em famílias, igrejas e pequenas comunidades, mas não cidadãos de uma república com objetivos comuns e obrigações uns para com os outros; II- Deve-se dar prioridade a acumular — em vez de distribuir — riqueza, o que permite que indivíduos e famílias mantenham sua independência e prosperem; III- Quanto mais livres são os mercados, mais eles crescem e enriquecem todo mundo; IV- O governo, para citar Reagan, "é o problema". Não o governo tirânico, não o governo ineficiente, não o governo injusto. Mas o governo em si (LILLA, 2018, p. 29).

No entorno dos mesmos fatos e com uma análise no âmbito da política institucional, Levitsky e Ziblatt em Como as Democracias Morrem (2018) discutem os fatores que foram 
determinantes para que Trump, um outsider, assumisse o maior cargo da política estadunidense.

Segundo os autores, a ascensão de Trump foi possibilitada por uma crise no interior dos partidos, estes que teriam até aquele momento contido, por meio do Colégio Eleitoral, a eleição de demagogos e extremistas tão populares quanto o candidato eleito em 2016. Contudo, para além disso, outros fatores foram determinantes para a vitória de Trump: a explosão da mídia alternativa, o elevado tempo de tela devido às falas polêmicas do então candidato (gerando propaganda eleitoral gratuita) e o financiamento externo da campanha (LEVITSKY; ZIBLATT, 2018). Aliadas a esses fatores, a internet e as redes sociais também exerceram papel crucial na campanha de Trump.

A construção da relação de demagogia entre Trump e seu eleitorado se deu principalmente por meio das redes sociais. Antes mesmo de ser oficialmente o candidato do Partido Republicano à presidência, a popularidade de sua possível candidatura era tão evidente que uma decisão interna do partido seria incapaz de contê-la sem consequências. Em entrevista ao jornalista Bob Woodward (2020), Trump diz:

\begin{abstract}
Sem as redes sociais, em primeiro lugar, eu não teria vencido, e em segundo, você sabe, eu estou em primeiro lugar no Facebook. Zuckerberg", o CEO do Facebook, "veio à Casa Branca há duas semanas." (...) "Disse, parabéns, você é número um no Facebook." (...) "E eu sou número um no Twitter," disse Trump. "Quando você é o número um e quando você tem centenas de milhões de pessoas, ainda que eles estejam contra você ou não, eles ainda leem o que você diz. Eu não preciso de comerciais. Quando você é número um, você não precisa de comerciais (WOODWARD, 2020, p. 232, tradução nossa).
\end{abstract}

Assim, nota-se que houve a construção de uma complexa relação entre Donald Trump e seu eleitorado, pautada no discurso populista e nas aparências cultivadas por ele, somadas à uma conjuntura institucional preexistente. O que viabilizou a eleição do republicano, como ele mesmo reconhece, foram as redes sociais.

A internet, criada inicialmente como um meio de comunicação entre computadores em uma rede fechada com fins militares, com nome inicial de Arpanet e que depois se estendeu aos computadores pessoais da sociedade civil, se desenvolveu de tal forma que atualmente podemos não apenas nos comunicar como também fazer compras, ler notícias e até mesmo produzir conteúdos, visto a horizontalidade que a internet proporciona entre os usuários, diferentemente dos meios tradicionais de comunicação, como o rádio ou a TV. Andrew Keen, um empresário do Vale do Silício (região do estado da Califórnia, nos Estados Unidos, que possui grande concentração de empresas de tecnologia), aponta para a importância da internet 
em nossas vidas atuais: "Primeiro vivemos em aldeias, depois em cidades; agora vivemos cada vez mais online" (KEEN, 2012, p. 50).

A atividade política assume um novo ambiente no século XXI. O papel da internet é preponderante na ascensão da chamada nova direita, na medida em que é essa a sua principal via de interação com o eleitorado (STURARI, 2020, p. 61), ao utilizar estratégias e mecanismos como as Fake News e o Big Data. Como a maior referência dessa lógica, a campanha (bem-sucedida) de Donald Trump para a presidência dos Estados Unidos em 2016 torna isso evidente. O Republicano foi eleito graças à habilidade na comunicação com seu público nas redes sociais, em que a importância da concretude dos fatos ficou em um plano secundário.

A campanha de Trump demonstra o uso da pós-verdade e justifica, junto com o BREXIT $^{4}$, ela ser escolhida a palavra do ano de 2016 do Dicionário Oxford. A prioridade na campanha de Trump era o apelo às paixões do povo americano, constituindo um forte caráter populista sob o slogan “Make America Great Again”. Sobre isso, em uma reportagem para o El País, afirmou Bassets à época da eleição:

Seu mérito consistiu em entender o desconforto dos norte-americanos vítimas da tempestade da globalização, as classes médias que não deixaram de perder poder aquisitivo nas últimas décadas, os que viram como a Grande Recessão paralisava a ascensão social, os que observam desconcertados as mudanças demográficas e sociais em um país cujas elites políticas e econômicas os ignoram. Os brancos da classe trabalhadora - uma minoria antigamente democrata que compete com outras minorias como os latinos e os negros, mas que não tem um status social de vítima - encontrou em Trump seu homem providencial. Também a corrente racista que existe no país da escravidão e da segregação encontrou em Trump um líder sob medida (BASSETS, 2016).

Desde o pleito eleitoral de 2016, a estratégia da Guerra Híbrida de manipular psicologicamente para instaurar o caos com fins políticos e legitimar o autoritarismo, tem sido a principal abordagem da comunicação entre presidente e estadunidenses. É dessa forma que Trump dissemina seu populismo; não é só um fator constante do mandato, mas a sustentação dele. Kakutani (2018, p. 12) demonstra essa estratégia ao afirmar que, sobre os usos da pósverdade e das Fake News por Trump:

As mentiras dele [...] são apenas o mais espalhafatoso entre os vários sinais de alerta acerca de seus ataques às instituições democráticas e normas vigentes. Ele ataca rotineiramente a imprensa, o sistema de justiça, as

${ }^{4}$ Referendo que marca a saída do Reino Unido da União Europeia. 
agências de inteligência, o sistema eleitoral e os funcionários públicos responsáveis pelo bom funcionamento do governo norte-americano.

Em 2018, o renomado jornalista norte-americano Bob Woodward lançou um livro sobre os primeiros anos de mandato de Donald Trump. Este livro é intitulado Fear. Contudo, o medo causado pelo presidente e relatado por Woodward não é o temor preconizado por Maquiavel. O florentino tratava de um temor derivado de uma força de autoridade do príncipe, que era consequência do "pavor do castigo" (MAQUIAVEL, 2018, p. 92), que evitaria uma possível insurreição do povo ou de inimigos. Já o medo causado pelo presidente norte-americano não é derivado dessa força de autoridade, mas da insegurança gerada pelo modo de governar. Esse medo, inclusive, não o defende das oposições, mas as causas, por ele ser temperamental, emocionalmente instável e impulsivo.

Tudo isso é potencializado no cenário de caos da saúde pública causado pela pandemia. Dessa forma, Trump vai contra um dos principais fundamentos da teoria maquiaveliana: "o príncipe deve inspirar medo de tal forma que, se não conquistar o amor, evitará o ódio" (MAQUIAVEL, 2018, p. 93).

Eu causo raiva. Eu realmente causo raiva. Eu sempre causei... Eu não sei se isso é uma vantagem ou uma desvantagem, mas qualquer que seja, eu causo. (...) Eu tive muitas situações assim, em que as pessoas me odiavam mais do que a qualquer ser humano que já conheceram (WOODWARD, 2020, p. 6).

Essa fala de Trump, de uma entrevista de 2016, dá nome ao segundo livro de Bob Woodward sobre o mandato do Republicano, Rage (raiva), em que ele trata da administração do presidente em 2020, com um enfoque na pandemia de Covid-19.

Trump pode ser considerado um governante odiado. No entanto, ele se mantém no poder porque é proporcionalmente amado por um setor específico e abrangente da sociedade americana: a classe média masculina e branca, que se encontra nos discursos ufanistas sobre salvar a pátria americana tradicional de uma destruição em potencial, que teria sido promovida pelas minorias.

A aceitação do presidente, porém, é menos relacionada à sua faculdade de governar, e mais ao seu bom uso da própria imagem nessa conjuntura política específica. Ele mesmo reconheceu seu populismo falho, quando revelou, em suas palavras, "não estar sentindo o amor" (CONRAD, 2020). O que promove sua aceitação, ainda que parcial, é a ocasião da internet, das Fake News e da pós-verdade.

Maquiavel recomenda que o príncipe possua determinadas qualidades, mas caso ele não as tenha, é necessário que, pelo menos, ele as aparente. O cenário virtual é o ambiente 
ideal para isso. Portanto, pode-se dizer que a internet potencializando as aparências, o faz também com a reputação positiva do príncipe, ou do presidente em nossa análise. Sobre essa questão, Sturari (2020) traz alguns pontos propostos pelo filósofo Byung-Chul Han, que fala sobre o que ele chama de sociedade da transparência, em um livro assim intitulado.

Para o autor, as coisas passam a ter valor por aquilo que se pode ver, ou seja, o apelo visual é fortíssimo. (...) Outro aspecto apontado por Han (op. cit.) é a perda da intimidade: com a alta publicização cria-se uma tirania que psicologiza e personaliza tudo, atravessando inclusive o meio da política; então, os políticos passam a ser julgados não por suas ações, mas por aquilo que encenam fazer (STURARI, 2020, p. 54-55, grifo nosso).

Kakutani (2018, p. 15-16) aponta, sobre essa questão ainda e já prenunciando a gestão da pandemia através das atitudes do presidente que

Com Trump, a esfera pessoal é política e, em muitos sentidos, ele é menos uma anomalia caricata e mais um bizarro epítome de uma série de atitudes mais amplas e interligadas que corroem lentamente a verdade nos dias de hoje, desde a mistura do noticiário e da política com o entretenimento até a polarização tóxica que tomou conta da política norte-americana, passando pelo crescente desprezo populista em relação ao conhecimento especializado.

Donald Trump usou isso ao seu favor para tentar manter sua aceitação em meio à pandemia. Em uma das 18 entrevistas que concedeu a Woodward, e que foram publicadas no livro Rage, Trump já demonstrava certa consciência sobre os perigos da ocasião. Essa consciência, contudo, não era o que ele manifestava publicamente; muito pelo contrário.

\section{Trump e a gestão da pandemia}

De acordo com uma das entrevistas de Woodward, no dia 28 de janeiro de 2020 Trump já teria sido avisado sobre o perigo iminente do vírus pelo seu Conselheiro de Segurança Nacional, Robert O’Brien, que o alertou dizendo que o vírus seria “a maior ameaça à segurança nacional". Em outra entrevista, no dia 6 de maio, Trump alegou não se lembrar de ter sido alertado; até lá, ele continuou afirmando à população que tinha controlado a situação por ter restringido o trânsito internacional com a China (GANGEL; HERB; STUART, 2020).

Em diversas situações, o presidente tentou demonstrar segurança nas suas medidas contra a crise. Ele procurou, em todos os seus pronunciamentos oficiais sobre a pandemia, atenuar a evidência de gravidade do vírus, afirmando publicamente que era como uma gripe 
comum. Além disso, atribuiu a sua cura, bem como a prevenção, a substâncias que não possuem comprovação científica de tais efeitos.

A hidroxicloroquina e a azitromicina foram tratadas por Trump como se fossem milagres na cura e na prevenção da Covid-19, tendência essa que foi reaproveitada por Bolsonaro no Brasil. O caminho de Trump até o endosso dessas substâncias é descrito por Bump (2020), em uma matéria do Washington Post, e é permeado por dados pós-verídicos (como um possível apoio da Universidade de Stanford, posteriormente desmentido publicamente pela mesma) e médicos agindo segundo interesses pessoais, sendo constantemente contrariados por publicações científicas. No Twitter, em 11 de maio, Trump escreve: "HYDROXYCHLOROQUINE \& AZITHROMYCIN, taken together, have a real chance to be one of the biggest game changers in the history of medicine"5.

Outra recomendação problemática do presidente foi o uso de desinfetante via oral para prevenção da doença, que levou portais de notícias a lançarem uma campanha para os cidadãos não tomarem desinfetante. Isso levou, inclusive, ao seu principal oponente nas eleições de 2020, Joe Biden, a se manifestar dizendo: "Não posso acreditar que tenha que dizer isto, mas, por favor, não bebam água sanitária” (GUIMÓN, 2020).

Tudo isso pode ser interpretado como uma tentativa de Trump de manter uma aparência de boa e efetiva gestão da pandemia, gerando, assim, maior aprovação por parte do seu eleitorado. O esforço para isso é tão grande que, em um de seus vídeos da campanha eleitoral de 2020, ele se utiliza de um pronunciamento feito pelo infectologista Anthony Fauci, principal cientista do governo, de forma manipulada, o que foi denunciado pelo próprio médico. Segundo reportagem veiculada em 12 de outubro na Globo News, o vídeo dá a entender que Fauci elogiava as medidas tomadas por Trump no enfrentamento da crise do Coronavírus, quando, na verdade, o pronunciamento era a respeito do trabalho realizado pela equipe de saúde da Casa Branca.

Apesar de sempre ter minimizado os efeitos da pandemia e supervalorizado sua competência para lidar com ela, numa entrevista concedida a Bob Woodward no dia 7 de fevereiro, antes da maioria desses pronunciamentos, foi dessa forma que ele se referiu à doença:

É transmitido pelo ar. É sempre mais complicado do que o toque. Você não precisa tocar as coisas. Certo? Mas o ar, você apenas respira o ar e é assim que se passa. E então essa é uma [doença] traiçoeira. Muito delicada. E é

${ }^{5}$ Livre tradução: "HIDROXICLOROQUINA \& AZITROMICINA, tomadas juntas, possuem chances reais de ser uma das maiores reviravoltas na história da medicina". 
também mais mortal que a sua gripe mais debilitante (GANGEL; HERB; STUART, 2020, tradução nossa).

Quando confrontado a respeito da ambivalência desses posicionamentos, Trump se posicionou da seguinte forma em outra entrevista a Woodward, no dia 19 de março, em gravação divulgada para a CNN: "Bom, eu acho, Bob, realmente, para ser sincero com vocêSempre quis minimizar sua [da pandemia] importância. Ainda gosto de minimizar porque não quero criar pânico" (GANGEL; HERB; STUART, 2020, tradução nossa).

O presidente dos Estados Unidos, nesse sentido, age prezando pelas aparências, mas não exatamente da maneira que o beneficie, como recomenda Maquiavel em $O$ Príncipe. Segundo ele, o príncipe deve parecer "piedoso, fiel, humano, religioso, [e] íntegro" (MAQUIAVEL, 2018, p. 97); o que, depreendendo da análise feita anteriormente, não é exatamente como Donald Trump se comporta. Além disso, o presidente aparenta ter sido mais piedoso nos aspectos que tentou esconder, e foram revelados nas entrevistas a Bob Woodward, do que no que escolheu mostrar nos pronunciamentos oficiais.

\section{Considerações finais}

Maquiavel estabeleceu preceitos sobre como o Príncipe deve se comportar e quais qualidades ele deve ter. Trazendo esses preceitos aos dias de hoje, podemos analisar a atuação do presidente estadunidense desde sua eleição, em 2016, até a gestão da pandemia e o período pré-eleitoral de 2020. Para isso trouxemos os conceitos de virtù e fortuna do filósofo florentino.

Talvez poucos ou nenhum analista político consideraria Trump um político virtuoso. Ele representa uma nova direita populista que tem conseguido vitórias globais, como Viktor Orbán na Hungria, Narendra Modi na Índia, Marine Le Pen na França (que apesar de não ter vencido as eleições que disputou recebeu quantidade considerável de votos), Bolsonaro no Brasil etc.

Trump encontrou a fortuna ao seu favor ao embarcar na onda conservadora que cresce no mundo e teve sucesso nas eleições através do uso da internet e das redes sociais, mesmo que por meios contestados (Kaiser (2019), aponta como o assessor de campanha de Trump, Steve Bannon, fez uso de mecanismos disponibilizados pela Cambridge Analytica para manipulação dos eleitores através dos dados disponibilizados na plataforma do Facebook. Também houve investigação sobre a possível ligação de Trump com a Rússia, que poderia ter influenciado a eleição estadunidense). 
Porém a fortuna que beneficiou Trump não durou muito, dando lugar à outra, a pandemia, que trouxe ameaças à sua estabilidade. Os Estados Unidos, um país rico e com um sistema de saúde elaborado, se viu fracassar na gestão da pandemia pelo presidente, que diminuiu a doença e se mostrou negacionista em relação aos dados que a ciência apresentava sobre o vírus e suas consequências (SINGER et al., 2021). Esse fracasso na gestão da pandemia provavelmente custou sua reeleição, mesmo sob as acusações de fraude que ele teceu para tentar continuar no cargo, o que ainda tem muito a ser estudado e analisado.

As controvérsias em seu governo foram muitas e são amplo campo de estudos e análises, muitas possibilidades em aberto. Porém, dentro do que aqui analisamos, podemos concluir que, sob os preceitos de virtù e fortuna, o presidente não era um exemplo do primeiro e o segundo se apresentou positivamente a ele de forma breve, como uma brisa passageira.

\section{REFERÊNCIAS}

BASSETS, M. Donald Trump vence as eleições de 2016 dos Estados Unidos. El País, 09 nov. 2016. Disponível em:

https://brasil.elpais.com/brasil/2016/11/09/internacional/1478660050_114058.html. Acesso em: 07 jan. 2021.

BIGNOTTO, N. Maquiavel republicano. São Paulo, SP: Edições Loyola, 1991. v. 19. (Coleção Filosofia)

BRUNELLO, A. R. The Measure of Machiavelli? Fear, Love, Hatred, and Trump. World Affairs, v. 4, n. 182, p. 324-349, 2019.

BUMP, P. The rise and fall of Trump's obsession with hydroxychloroquine. The Washington Post, 24 abr. 2020. Disponível em:

https://www.washingtonpost.com/politics/2020/04/24/rise-fall-trumps-obsession-withhydroxychloroquine/. Acesso em: 07 jan. 2021.

CONRAD, P. Rage by Bob Woodward review - Trump unleashed. The Guardian, 21 set. 2020. Disponível em: https://www.theguardian.com/books/2020/sep/21/rage-by-bobwoodward-review-trump-unleashed. Acesso em: 07 jan. 2021.

GANGEL, J.; HERB, J.; STUART, E. 'Play it down': Trump admits to concealing the true threat of coronavirus in new Woodward book. CNN Politics, 10 set. 2020. Disponível em: https://edition.cnn.com/2020/09/09/politics/bob-woodward-rage-book-trumpcoronavirus/index.html. Acesso em: 07 jan. 2021.

GUIMÓN, P. "Por favor, não comam pastilhas de detergente nem se injetem nenhum tipo de desinfetante", pedem médicos. El País, 25 abr. 2020. Disponível em:

https://brasil.elpais.com/internacional/2020-04-25/por-favor-nao-comam-pastilhas-de- 
detergente-nem-se-injetem-nenhum-tipo-de-desinfetante-alertam-medicos.html. Acesso em: 07 jan. 2021.

JARMAN, H. State Responses to the COVID-19 Pandemic: Governance, Surveillance, Coercion, and Social Policy. In: GREER, S. L.; KING, E. J.; FONSECA, E. M. (org.) Coronavirus politics: the comparative politics and policy of Covid-19. Ann Arbor, MI: University of Michigan Press, 2021. p. 51-64.

KAISER, B. Manipulados: como a Cambridge Analytica e o Facebook invadiram a privacidade de milhões e botaram a democracia em xeque. Rio de Janeiro, RJ: Harper Collins, 2020.

KAKUTANI, M. A morte da verdade. Rio de Janeiro, RJ: Intrínseca, 2018.

KEEN, A. Vertigem digital: por que as redes sociais estão nos dividindo, diminuindo e desorientando. Rio de Janeiro, RJ: Zahar, 2012.

KESSLER, G.; RIZZO, S.; KELLY, M. President Trump has made 4229 false or misleading claims in 558 days. The Washington Post, 01 ago. 2018. Disponível em:

https:/www.washingtonpost.com/news/fact-checker/wp/2018/08/01/president-trump-hasmade-4229-false-or-misleading-claims-in-558-days/?utm_term=.1dd92b97fb86. Acesso em: 07 jan. 2021.

LEE, T. The global rise of "fake news" and the threat to democratic elections in the USA.

Public Administration and Policy: An Asia-Pacific Journal, v. 22, n. 1, p. 15-24, 2019.

LEVITSKY, S.; ZIBLATT, D. Como as democracias morrem. Rio de Janeiro, RJ: Zahar, 2018.

LILLA, M. O progressista de ontem e o do amanhã: desafios da democracia liberal no mundo pós políticas identitárias. São Paulo, SP: Cia das Letras, 2018.

MAQUIAVEL, N. O príncipe. Barueri, SP: Novo Século Editora, 2018.

SINGER, P. M. et al. Anatomy of a failure: Covid-19 in the United States. In: GREER, S. L.; KING, E. J.; FONSECA, E. M. (org.) Coronavirus politics: the comparative politics and policy of Covid-19. Ann Arbor, MI: University of Michigan Press, 2021. p. 478-49.

STURARI, V. S. Redes e manifestações: novos repertórios e atores. 2020. Dissertação (Mestrado em Ciências Sociais) - Faculdade de Ciências e Letras, Universidade Estadual Paulista, Araraquara, SP, 2020.

WOODWARD, B. Rage. Nova York: Simon \& Schuster, 2020. 


\section{Como referenciar este artigo}

MOUTROPOULOS, J. V.; STURARI, V. S. A internet poderia prometer honras a um príncipe novo? Donald Trump e a pandemia de COVID-19 nos Estados Unidos. Rev. Sem Aspas, Araraquara, v. 10, e021002, jan./dez. 2021. e-ISSN: 2358-4238. DOI: https://doi.org/10.29373/sas.v10i00.14630

Submetido em: 09/01/2021

Aprovado em: 22/05/2021

Publicado em: 30/06/2021 